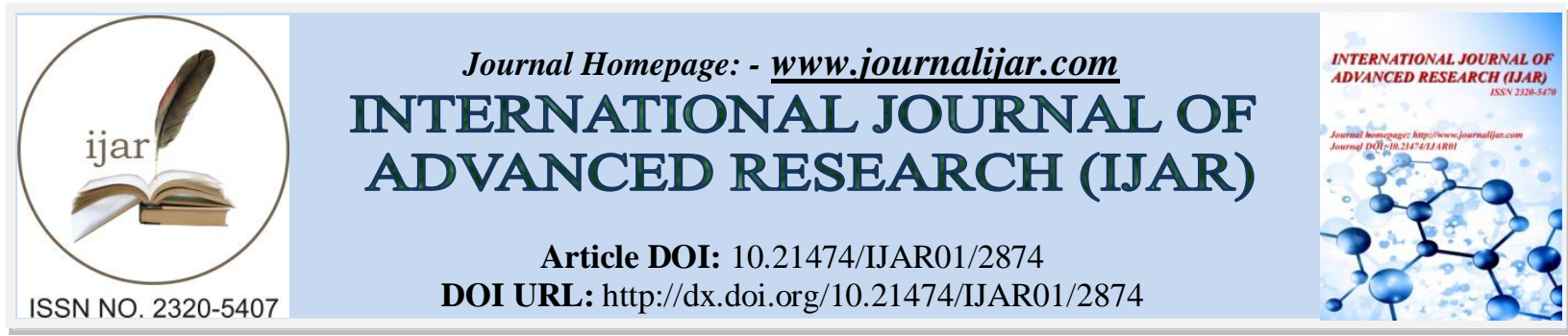

RESEARCH ARTICLE

\title{
PREVALENCE AND AWARENESS OF OBESITY AMONG SAUDI FEMALE IN RIYADH, SAUDI ARABIA.
}

\section{Sarah Almohsen ${ }^{1}$, Norah Alfahad ${ }^{2}$, Malak Alenazi ${ }^{1}$, Majeedah Alotaibi ${ }^{3}$, Hala Alrqib ${ }^{4}$ and Shaikha Bohamod ${ }^{1}$.}

1. College of Medicine, King Saud University Riyadh, Saudi Arabia.

2. Department of medicine, National Guard Hospital, Riyadh, Saudi Arabia.

3. Department of ophthalmology, King Saud medical city, Riyadh, Saudi Arabia.

4. Department of medicine, prince sultan military medical city, Riyadh, Saudi Arabia.

\section{Manuscript Info}

Manuscript History

Received: 21 November 2016

Final Accepted: 21 December 2016

Published: January 2017

Key words:-

Obesity, Females, Knowledge, prevalence

\section{Abstract}

Background: Despite knowing the seriousness of obesity and its impact on health, its prevalence still growing in Saudi Arabia, which puts a considerable financial burden on governments and individuals resources

Objective: to determine the prevalence of obesity among Saudi female in Riyadh city, Find out level of awareness among women regarding obesity and its problems.

Methods: A cross-sectional study among Saudi female in Riyadh. Selfadministered pretested questionnaire was distributed in six major shopping malls in January, 2011. The administered questionnaire included the demographic data, anthropometric measurements, questions to assess the knowledge of participants about obesity.

Results: Total of 174 female participants included in study, mean age was 22 years. $59 \%$ of participants have collage level education, $50 \%$ high school education .For marital status , 63\% of participant were married . Regarding the participants weight, $33.3 \%$ were overweight (BMI 25-30) and 28\% were obese (above 30). Most of participants reported High caloric intake (96\%) and Lack of physical activity $(92 \%)$ as the main risk factor for obesity. For health consequences and complication of obesity, Most of participants reported hypertension, stroke, heart disease, and DM as the main health consequence for obesity with percentage of $79 \%, 70 \%, 73 \%, 70 \%$ respectively. While $30 \%, 26 \%$ and $10 \%$ reported cancer, sleep apnea and Gynecological problems as health problem related to obesity (respectively).

Conclusion: Obesity is a real public health problem among Saudi female that need control strategies through life style modification and medical intervention. Knowledge of the health consequences of obesity among Saudi female were high about cardiovascular risk but poor about cancer, Osteoarthritis, sleep apnea and Gynecological risk. 


\section{Introduction:-}

Obesity is a major health problem that associated with decreases in life expectancy and health-related quality of life (1). In 2014, WHO estimated that more than 1.9 billion of adults around the world were overweight and over 600 million were obese (2). Locally, Prevalence of overweight and obesity in Saudi female above age of 15 years is reported to be $28.8 \%$ and $33 \% 10.6 \%$, respectively (3).

Obesity have strong relationship with many risk factor including hormones, low socioeconomic status, smoking , high media times and high intake of food though the strength of the relationship varies with the condition (4-5).

Furthermore, obesity associated with multiple co-morbidities including cardiovascular, endocrine, pulmonary, sleep apnea, arthritis, gastrointestinal, gall bladder disease, and certain types of cancer (6).

Despite knowing the seriousness of obesity and its impact on health, its prevalence still growing (7). This increase obesity rate put a considerable financial burden on governments and individuals resources (8). Knowing the prevalence rates and level of societies awareness is therefore a major step to the development of useful interventions methods to minimize this health problem.

The objective of this study was to determine the prevalence of obesity among Saudi female, Find out level of awareness among women regarding obesity and its problems.

\section{Methods:-}

A cross-sectional study was conducted among Saudi female in Riyadh. Self-administered pretested questionnaire was distributed in six major shopping malls (Granada mall, Hayat mall, Panorama mall, Sahara mall, Alothaim mall and Riyadh gallery) in January, 2011. The coded questionnaires had unique identification numbers to keep the anonymity of participants. In each of the six malls, 29 questionnaires were distributed over visitor. The purpose of the study were explained to participants and written consent obtained from female, who agreed to participate in the study. The final questionnaire was developed after pilot testing among 30 Saudi female and necessary modifications were done. The Inclusion criteria for study were Saudi females, ages 18 and older, living in Riyadh city and not working in the medical field.

The administered questionnaire included the following sections:

a. Demographic data: age, marital status, education level

b. Anthropometric Measurements: Body weight was measured using a bathroom scale. Height was measured using a stadiometer then Body mass index was calculated for each subject as the ratio of body weight (in $\mathrm{kg}$ ) and squared height (in metres). A participant was considered to be obese or not by using the BMI criteria Suggested by Beaton et al. BMI less than $18.5 \mathrm{~kg} / \mathrm{m}^{2}$ was considered underweight, between 18.5 and $25 \mathrm{~kg} / \mathrm{m}^{2}$ was considered normal, $25-30 \mathrm{~kg} / \mathrm{m}^{2}$ was considered overweight, and $30 \mathrm{~kg} / \mathrm{m}^{2}$ or above was considered obese.

c. Knowledge of participants: was assessed by asking them about different aspects of obesity including risk factor, various medical conditions and cancers associated with obesity, management of obesity.

The ethics committees at a collage approved this study. Each participant received a thorough explanation of the purpose of the study and written consent obtained from each participant the participants was told that the enrollment is voluntary.

The survey responses were entered into the SPSS software (version 17.0) and checked for any errors or missing information. Demographic characteristics were assessed using means for continuous variables and proportions for categorical variables. Knowledge about disease risk was assessed using proportions. Analysis of variance test used to assess differences in obesity awareness by demographic Variables (marital status, age).

\section{Results:-}

Total of 174 female participants included in study, mean age was 22 years, the age ranged from 18 to 54 years. $59 \%$ of participants have collage level education, $50 \%$ high school education and $16 \%$ postgraduate level education. For marital status, $63 \%$ of participants were married while $36.7 \%$ were singles. Regarding the participants weight, 4.5 $\%$ were underweight with body mass index below 18.5, $34 \%$ were normal weight (BMI between 18.5-25) , 33.3\% 
were overweight (BMI 25-30) and 28\% were obese (above 30). Table 1 showed demographic data and BMI of participant.

Table 1: Demographic data and BMI.

\begin{tabular}{|c|c|c|c|}
\hline \multirow{3}{*}{ Age } & $18-25$ & 79 & $45.4 \%$ \\
\cline { 2 - 4 } & $26-40$ & 56 & $32 \%$ \\
\cline { 2 - 4 } & Above 40 & 39 & $22.4 \%$ \\
\hline \multirow{4}{*}{ Education } & Illiterate & 2 & $1 . \%$ \\
\cline { 2 - 4 } & Primary \& Middle school \& & 3 & $1.7 \%$ \\
\cline { 2 - 4 } & high school & 50 & $28.7 \%$ \\
\cline { 2 - 4 } & Collage & 103 & $59 . \%$ \\
\cline { 2 - 4 } & Post graduate & 16 & $9 \%$ \\
\cline { 2 - 4 } & Under weight & 5 & $4.5 \%$ \\
\cline { 2 - 4 } & Normal weight & 58 & $34 \%$ \\
\cline { 2 - 4 } & overweight & 49 & $28 \%$ \\
\hline \multirow{3}{*}{ BMI } & obese & 64 & $36.7 \%$ \\
\cline { 2 - 4 } & single & 110 & $63 \%$ \\
\hline
\end{tabular}

Regarding participants knowledge about the risk factors of obesity ,most of participants reported High caloric intake (96\%) and Lack of physical activity (92\%) as the main risk factor while 56.8\% reported Insufficient sleep , 56.8\% psychiatric illness $48.8 \%$ Genetic susceptibility $52.8 \%$ Drugs and 47.7 Age 40 as risk factors. For health consequences and complication of obesity, Most of participants reported hypertension, stroke, heart disease, and $\mathrm{DM}$ as the main health consequence for obesity with percentage of $79 \%, 70 \%, 73 \%, 70 \%$ respectively. While $30 \%$, $26 \%$ and $10 \%$ reported cancer, sleep apnea and Gynecological problems as health problem related to obesity (respectively). Regarding obesity preventative measures, $96 \%$ and $93 \%$ of responder reported Healthy diet and regular exercise as main preventative measures (respectively).Table 2 showed Percentage of Participants having Correct Knowledge about obesity Risk Factors and health consequences.

Table 2:- Percentage of Participants having Correct Knowledge about obesity Risk Factors, preventative measure and health consequences

\begin{tabular}{|l|l|l|l|}
\hline \multirow{5}{*}{ Risk factor } & Lack of physical activity & 161 & $92 \%$ \\
\cline { 2 - 4 } & Insufficient sleep & 99 & $56.8 \%$ \\
\cline { 2 - 4 } & psychiatric illness & 85 & $48.8 \%$ \\
\cline { 2 - 4 } & Genetic susceptibility & 92 & $52.8 \%$ \\
\cline { 2 - 4 } & Drugs such as steroids, OCP & 83 & 47.7 \\
\cline { 2 - 4 } & High caloric intake & 168 & 96 \\
\cline { 2 - 4 } & Age & 70 & 40 \\
\hline \multirow{5}{*}{ Health consequences } & Hypertension & 138 & $79 \%$ \\
\cline { 2 - 4 } & Stroke & 122 & $70 \%$ \\
\cline { 2 - 4 } & Heart disease & 128 & $73 \%$ \\
\cline { 2 - 4 } & Cancer & 52 & $30 \%$ \\
\cline { 2 - 4 } & DM & 121 & $70 \%$ \\
\cline { 2 - 4 } & Osteoarthritis & 45 & $26 \%$ \\
\cline { 2 - 4 } & sleep apnea & 78 & $10 \%$ \\
\cline { 2 - 4 } & Gynecological problems & 19 & $96.5 \%$ \\
\hline & Healthy diet & 168 & $93 \%$ \\
\cline { 2 - 4 } & Regular exercise & 162 & $50 \%$ \\
\cline { 2 - 4 } & Meditation & 87 & $28.7 \%$ \\
\cline { 2 - 4 } & Regular health check-ups & 90 & \\
\cline { 2 - 4 } & stress management & 50 & $2.7 \%$ \\
\hline
\end{tabular}

Most of participants (57\%) between age of 18 to 25 were non obese. In contrast, 74.3 of the participants above 40 years were obese $(\mathrm{p}<0.001)$. Among married female, $29 \%$ were non obese, $38 \%$ overweight and 36.3 were obese while single female $54.6 \%$ non obese $31 \%$ overweight and $14 \%$ obese ( $\mathrm{p}=0.001)$. Tables 3 and 4 . 
Table 3:- Relationship between obesity and age of participant.

\begin{tabular}{|c|c|c|c|c|}
\hline Age & Non obese & Overweight & Obese & Total \\
\hline $18-25$ & $45(57 \%)$ & $29(36.7 \%)$ & $5(6 \%)$ & $79(100 \%)$ \\
\hline $26-40$ & $19(34 \%)$ & $22(39.2 \%)$ & $15(26.7 \%)$ & $56(100 \%)$ \\
\hline Above 40 & $3(7.6 \%)$ & $7(18 \%)$ & $29(74.3)$ & $39(100 \%)$ \\
\hline Total & $67(100 \%)$ & $58(100 \%)$ & $49(100 \%)$ & 174 \\
\hline
\end{tabular}

$\mathrm{P}<0.001$

Table 4:- Relationship between obesity and marital status of participant.

\begin{tabular}{|c|c|c|c|c|}
\hline Marital status & Non obese & Overweight & Obese & total \\
\hline Single & $35(54.6 \%)$ & $20(31.2 \%)$ & $9(14 \%)$ & 64 \\
\hline Married & $32(29 \%)$ & $38(34 \%)$ & $40(36.3 \%)$ & 110 \\
\hline Total & 67 & 58 & 49 & 174 \\
\hline
\end{tabular}

$\mathrm{P}=0.001$

\section{Discussion:-}

This study aimed to determine the prevalence of obesity among Saudi female and to assess the level of awareness among Saudi women regarding obesity and its problems. This small scale study is unique in certain ways as the study was conducted at the capital city of Saudi Arabia, in the largest malls of city which is a destination of all society spectrums and made this study as representative of obesity prevalence and level of awareness.

Prevalence of obesity in our study reported to be $28 \%$, this is almost consistent with previously reported among Saudi female (33\%) (3). This shows that obesity is major public health problem among Saudi female, that need control strategies and not to be ignored.

BMI increases in direct proportion with age, in which participants above age of 40 have the greatest rate of obesity followed by age of 25 to 40. Similar conclusion reported previously (9). The reason behind this could be due to decline in physical activity with age in addition to menopause that associated with Weight gain and changes in fat distribution (10).

In current study, marital status was associated with higher BMI, several studies reported similar association between marriage and increased prevalence of obesity (11-12). The explanation for this finding could be because married couples tend to eat regularly with their children and they have better eating pattern and high caloric intake. Sobal $\mathbf{J}$ etal reported strong association between marital status and obesity only among men, but not among female (13).

In our study between $70 \%$ to $79 \%$ of subjects were aware that obesity increase risk of hypertension, cardiac disease, stroke and diabetes. Eden R Cardozo etal reported similar finding for awareness of cardiovascular disease and DM in obese subject (14). Ginger J. Winston reported slightly higher level of awareness (94\%-96\%) (15).in our study, we found lower level of awareness among participants about the association of cancer and Gynecological problems to obesity and this finding reported globally $(\mathbf{1 4}, \mathbf{1 6})$.

The limitation of study included study design as the cross sectional study may give a different results if another time-frame has been chosen

In summary, Obesity is a real public health problem among Saudi female that need control strategies through life style modification and medical intervention. Our findings indicated that Saudi females were knowledgeable about association between obesity and increased risk of cardiovascular, diabetes in contrast level of awareness about obesity and risk of cancer, Osteoarthritis, sleep apnea and Gynecological problems were poor. 


\section{References:-}

1. Peeters A. Obesity in Adulthood and Its Consequences for Life Expectancy: A Life-Table Analysis. Annals of Internal Medicine. 2003;138(1):24.

2. World Health Organization. Obesity. 2008. Available at: http://www.who.int/topics/obesity/en/.

3. Memish ZA, El Bcheraoui C, Tuffaha M, Robinson M, Daoud F, Jaber S, et al. Obesity and associated factors Kingdom of Saudi Arabia, 2013. Prev Chronic Dis 2014;11:E174.

4. Antia FP. Clinical dietetics and nutrition. Oxford University Press, London, 1989.

5. Kleiser C, Schaffrath Rosario A, Mensink G, Prinz-Langenohl R, Kurth B. Potential determinants of obesity among children and adolescents in Germany: results from the cross-sectional KiGGS study. BMC Public Health. 2009;9(1):46.

6. PI-SUNYER F. Comorbidities of overweight and obesity: current evidence and research issues. Medicine \& Science in Sports \& Exercise. 1999;31(Supplement 1):S602.

7. Williams E, Mesidor M, Winters K, Dubbert P, Wyatt S. Overweight and Obesity: Prevalence, Consequences, and Causes of a Growing Public Health Problem. Current Obesity Reports. 2015;4(3):363-370.

8. Withrow D, Alter DA. The economic burden of obesity worldwide: a systematic review of the direct costs of obesity. Obesity Reviews. 2011;12(2):131-141.

9. Nyaruhucha C, Achen J, Msuya J, Shayo N, Kulwa K. Prevalence and awareness of obesity among people of different age groups in educational institutions in Morogoro, Tanzania. East African Medical Journal. 2004;80(2).

10. Torng P, Su T, Sung F, Chien K, Huang S, Chow S et al. Effects of menopause and obesity on lipid profiles in middle-aged Taiwanese women: the Chin-Shan Community Cardiovascular Cohort Study. Atherosclerosis. 2000;153(2):413-421.

11. Fitzgibbons Shafer E. The Effect of Marriage on Weight Gain and Propensity to Become Obese in the African American Community. Journal of Family Issues. 2010;31(9):1166-1182.

12. Lipowicz A, Gronkiewicz S, Malina R. Body mass index, overweight and obesity in married and never married men and women in Poland. American Journal of Human Biology. 2002;14(4):468-475.

13. Sobal J, Rauschenbach B, Frongillo E. Marital status, fatness and obesity. Social Science \& Medicine. 1992;35(7):915-923.

14. Cardozo E, Dune T, Neff L, Brocks M, Ekpo G, Barnes R et al. Knowledge of Obesity and Its Impact on Reproductive Health Outcomes Among Urban Women. Journal of Community Health. 2012;38(2):261-267.

15. Winston G, Caesar-Phillips E, Peterson J, Wells M, Martinez J, Chen X et al. Knowledge of the health consequences of obesity among overweight/obese Black and Hispanic adults. Patient Education and Counseling. 2014;94(1):123-127.

16. Thapa J, Lyford C, McCool B, Pence B, McCool A, Belasco E. Improving Cancer Risk Awareness Including Obesity as a Risk Factor for Cancer in a Small U.S. Community. J Cancer Educ. 2016 Jun 11. [Epub ahead of print] 